\title{
Motivations for Smoking Cessation: A Comparison of Successful Quitters and Failures
}

\author{
Michael T. Halpern \\ Battele Memorial Institute \\ Washington, DC \\ Kenneth E. Warner \\ The University of Michigan
}

\begin{abstract}
To foster successful smoking cessation, public health professionals need to understand better the reasons why smokers quit smoking. Although researchers have studied smokers' characteristics that may predict smoking cessation, few studies have examined the relationships between reasons stated for quitting and successful smoking cessation.

We examined six reasons for smoking cessation and their association with successfully quitting among approximately 7,700 current and former smokers who participated in the 1986 Adult Use of Tobacco Survey (AUTS). Using logistic regression analysis, we found that successful cessation was associated with having personal concerns regarding the health effects of smoking and with wanting to set a good example for children. In contrast, concerns about the cost of smoking, the effect of smoking on others, and pressure from friends and family to quit were associated with decreased likelihoods of cessation. Furthermore, the relative importance of a reason (somewhat important vs. very important) also influenced the association of that reason with smoking cessation.
\end{abstract}

Approximately 1.3 million cigarette smokers successfully quit smoking each year in the U.S. (Fiore et al., 1990). As many as another 15 million make a serious attempt to quit but fail (USDHHS, 1989). As efforts intensify to foster successful quitting, public health professionals need to understand better smokers' motivations for quitting and to appreciate how such motivations may differ among smokers from different social and economic backgrounds. Although analysts have examined demographic correlates of smoking cessation (Freund, D'Agostino, Belanger, Kannel, \& Stokes, 1992; Kabat \& Wynder, 1987; McWhorter, Boyd, \& Mattson, 1990), there have been few studies of the relationship between successful smoking cessation and reasons for quitting (Gilpin, Pierce, Goodman, Burns, \& Shopland, 1992). Drawing on data from a major national study of tobacco use, we have examined these relationships in a multiple logistic regression analysis.

\section{METHODS}

Data on exsmokers' sociodemographic characteristics and reasons for smok-

Correspondence and requests for reprints should be sent to Michael T. Halpern, Battelle MEDTAP, 901 D Street SW, Suite 900, Washington, DC 90024. 
ing cessation were derived from the 1986 Adult Use of Tobacco Survey (AUTS), which was described previously (USDHHS, 1990). Briefly, the AUTS collected data from 13,013 individuals using random digit dialing. Individuals 17 years of age or older in all 50 states were the target population. Ever smokers (current smokers and former smokers, defined as respondents who had previously smoked at least 100 cigarettes) were oversampled 3:1 with respect to never smokers to increase the number of ever smokers in the survey population. Smoking status was designated by self-report. For this study, all former smokers and current smokers with at least one serious quit attempt (by self-report) were included in the study population.

We used multiple logistic regression (SAS LOGIST procedure; SAS Institute, 1986) of unweighted data to examine the relationships between successful smoking cessation (former smoker status, the dependent variable) and respondents' reasons for smoking cessation. Former smokers and current smokers with at least one serious quit attempt were asked whether each of six reasons was important in quitting smoking (former smokers) or attempting to quit smoking (current smokers with serious quit attempts). These six reasons were: (1) concern about the current health effects of smoking for the smoker; (2) concern about the future health effects of smoking for the smoker; (3) the desire to set a good example for children; (4) cost of smoking, (5) the effect of smoking on others' and (6) pressure from family and friends to quit. When respondents answered that one of these reasons was important in their quitting or attempting to quit, they were then asked if the reason was somewhat important or very important. Respondents could choose any number of these reasons as important, including none or all. These six reasons constituted the entire universe of reasons asked of each respondent. Respondents were allowed to specify other reasons beyond these six; however, no more than $5 \%$ of respondents provided any one additional reason.

Each reason for smoking cessation was examined in a separate regression model. The dependent variable in each regression was smoking-cessation success (former smoker status). In one set of regressions, an independent variable simply indicated that a given reason was important to the quitter or attempted quitter (level of importance not being specified). In another set of regressions, two independent variables distinguished between the levels of importance of a given reason (i.e., the reason being somewhat important or very important). Other independent variables included in each model were gender, age, minority status (non-Caucasian), family income $(<\$ 20,000$ vs. $\geq \$ 20,000)$, education level (highest grade of schooling completed, recoded as not graduating high school, high school graduate, some college, or college graduate), smoking characteristics (years smoked and number of cigarettes per day), and number of other reasons given for smoking cessation. Years smoked was coded $<16$ years versus $\geq 16$ years, split at the median value. As described by Coambs, Li, and Kozlowski (1992), daily consumption of cigarettes was coded as $<25$ cigarettes versus $\geq 25$ cigarettes in order to isolate a group that reports smoking more than the typical smoker does, but is large enough for statistical purposes. As Coambs et al. further described, there is a significant age interaction with intensity of smoking as regards to success in quitting: younger lighter smokers and older heavier 
smokers have greater likelihoods of quitting. Therefore, the model also contained the interaction of age and daily consumption.

\section{RESULTS}

Table 1 shows the distribution of demographic and smoking characteristics of current and former smokers from the AUTS. Although current smokers were approximately evenly distributed between men and women, the majority of former smokers were men. This is consistent with previous findings that men have been more likely to quit smoking successfully than women (USDHHS, 1989). Current smokers tended to be younger, more likely to be minority members, poorer, less highly educated, and more likely to have smoked for at least 16 years as compared to former smokers, also consistent with previous studies

Table 1. Distribution of AUTS Respondent Characteristics

\begin{tabular}{|c|c|c|c|c|}
\hline & \multicolumn{2}{|c|}{$\begin{array}{l}\text { Current } \\
\text { Smoker }\end{array}$} & \multicolumn{2}{|c|}{$\begin{array}{l}\text { Former } \\
\text { Smoker } \\
\end{array}$} \\
\hline & $n$ & $(\%)$ & $n$ & $(\%)$ \\
\hline Total & 3080 & & 4614 & \\
\hline $\begin{array}{l}\text { Gender } \\
\text { Male } \\
\text { Female }\end{array}$ & $\begin{array}{l}1528 \\
1552\end{array}$ & $\begin{array}{l}(49.6) \\
(50.4)\end{array}$ & $\begin{array}{l}2606 \\
2008\end{array}$ & $\begin{array}{l}(56.5) \\
(43.5)\end{array}$ \\
\hline $\begin{array}{l}\text { Age } \\
17-29 \\
30-39 \\
40-49 \\
50-59 \\
60-69 \\
70-97\end{array}$ & $\begin{array}{l}728 \\
897 \\
620 \\
400 \\
306 \\
129\end{array}$ & $\begin{array}{r}(23.6) \\
(29.1) \\
(20.1) \\
(13.0) \\
(9.9) \\
(4.2)\end{array}$ & $\begin{array}{r}609 \\
1013 \\
816 \\
762 \\
832 \\
582\end{array}$ & $\begin{array}{l}(13.2) \\
(22.0) \\
(17.7) \\
(16.5) \\
(18.0) \\
(12.6)\end{array}$ \\
\hline $\begin{array}{l}\text { Minority Status } \\
\text { Minority } \\
\text { Nonminority }\end{array}$ & $\begin{array}{r}470 \\
2610\end{array}$ & $\begin{array}{l}(15.3) \\
(84.7)\end{array}$ & $\begin{array}{r}538 \\
4076\end{array}$ & $\begin{array}{l}(11.7) \\
(88.3)\end{array}$ \\
\hline $\begin{array}{l}\text { Family Income } \\
<\$ 20,000 \\
\geq \$ 20,000\end{array}$ & $\begin{array}{r}965 \\
1904\end{array}$ & $\begin{array}{l}(31.3) \\
(61.8)\end{array}$ & $\begin{array}{l}1207 \\
3013\end{array}$ & $\begin{array}{l}(26.2) \\
(65.3)\end{array}$ \\
\hline $\begin{array}{l}\text { Education } \\
\text { Non-high-school graduate } \\
\text { High school graduate } \\
\text { Some college } \\
\text { College graduate }\end{array}$ & $\begin{array}{r}593 \\
1220 \\
787 \\
472\end{array}$ & $\begin{array}{l}(19.3) \\
(39.6) \\
(25.6) \\
(15.3)\end{array}$ & $\begin{array}{r}825 \\
1502 \\
1089 \\
1177\end{array}$ & $\begin{array}{l}(17.9) \\
(32.6) \\
(23.6) \\
(25.5)\end{array}$ \\
\hline $\begin{array}{l}\text { Smoking characteristics } \\
<25 \mathrm{cig} / \text { day } \\
\geq 25 \mathrm{cig} / \text { day } \\
\text { Smoked }<16 \text { years } \\
\text { Smoked } \geq 16 \text { years }\end{array}$ & $\begin{array}{r}2151 \\
929 \\
1174 \\
1904\end{array}$ & $\begin{array}{l}(69.8) \\
(30.2) \\
(38.1) \\
(61.8)\end{array}$ & $\begin{array}{l}3209 \\
1405 \\
2156 \\
2184\end{array}$ & $\begin{array}{l}(69.6) \\
(30.5) \\
(46.7) \\
(47.3)\end{array}$ \\
\hline
\end{tabular}

Note. Percentages may not sum to $100 \%$ due to missing data. 
(Klesges et al., 1988; USDHHS, 1989). There was virtually no difference in the percentages of current versus former smokers smoking at least 25 cigarettes per day.

Table 2 shows responses to the six reasons for smoking cessation and the number of reasons responded to affirmatively. For both current and former smokers, health concerns (both present and future) had the greatest number of affirmative responses. Effect on others was third for each group. Approximately equal numbers of current smokers replied affirmatively to each of the three remaining reasons. Among former smokers, however, example for children drew more affirmative replies than did either cost or pressure from friend and family. A greater percentage of current than former smokers replied affirmatively to each of the reasons. As seen in the lower half of Table 2, current smokers generally replied affirmatively to more reasons than did former smokers $(M=2.97$ and 2.55 for current and former smokers, respectively, $p<.0001)$.

Table 3 presents results from a baseline logistic regression model examining demographic correlates with successful smoking cessation. Results are presented as odds ratios. A statistically significant odds ratio greater than 1.0 for a given characteristic indicates that respondents with that characteristic were more likely to have quit smoking than were respondents lacking the characteristic; significant odds ratios less than 1.0 indicate decreased likelihood of smoking cessation

Table 2. Distribution of AUTS Reasons for Smoking Cessation

\begin{tabular}{|c|c|c|c|c|}
\hline & \multicolumn{2}{|c|}{$\begin{array}{l}\text { Current } \\
\text { Smoker }\end{array}$} & \multicolumn{2}{|c|}{$\begin{array}{l}\text { Former } \\
\text { Smoker }\end{array}$} \\
\hline & $n$ & $(\%)$ & $n$ & $(\%)$ \\
\hline Total & 3080 & & 4614 & \\
\hline \multicolumn{5}{|l|}{ Reasons for smoking cessation" } \\
\hline Present health & 1969 & $(63.9)$ & 3740 & $(59.4)$ \\
\hline Future health & 2466 & $(80.1)$ & 3436 & $(74.5)$ \\
\hline Example for children & 1103 & (35.8) & 1590 & $(34.5)$ \\
\hline Cost & 1110 & $(36.0)$ & 1149 & $(24.9)$ \\
\hline Effect on others & 1401 & $(45.5)$ & 1650 & $(35.8)$ \\
\hline Pressure from family and friends & 1063 & $(34.5)$ & 1171 & (25.4) \\
\hline \multicolumn{5}{|l|}{$\begin{array}{l}\text { Number of reasons stated } \\
\text { for smoking cessation }\end{array}$} \\
\hline 0 & 233 & $(7.6)$ & 463 & $(10.0)$ \\
\hline 1 & 419 & $(13.6)$ & 776 & (16.8) \\
\hline 2 & 638 & $(20.7)$ & 1185 & (25.7) \\
\hline 3 & 587 & $(19.1)$ & 907 & (19.7) \\
\hline 4 & 520 & (16.9) & 683 & (14.8) \\
\hline 5 & 426 & $(13.8)$ & 439 & (9.5) \\
\hline 6 & 241 & (7.8) & 157 & (3.4) \\
\hline
\end{tabular}

a Number responding yes to each as a "reason important to respondent to quit smoking" (USDHHS, 1990). 
Table 3. Demographic Factors Associated With Smoking Cessation

\begin{tabular}{|c|c|}
\hline Demographic Factors & Odds Ratios \\
\hline Female & $0.74 * * *$ \\
\hline Age (10 years older) & $2.19 * * * *$ \\
\hline Minority & 0.94 \\
\hline Income & $1.47 * * * *$ \\
\hline High school & $1.19 *$ \\
\hline Some college & $1.29 * *$ \\
\hline College graduate & $2.15^{* * * *}$ \\
\hline Smoked $\geq 16$ years & $0.11 * * * *$ \\
\hline Heavy smoker ( $\geq 25 \mathrm{cig} /$ day $)$ & $0.68^{*}$ \\
\hline Interaction of age with heavy smoker & $1.15 * *$ \\
\hline \multicolumn{2}{|l|}{$\begin{array}{l}\text { Number of Reasons for Cessation } \\
\text { (relative to none of the six reasons) }\end{array}$} \\
\hline 1 & 1.12 \\
\hline 2 & $1.29 *$ \\
\hline 3 & 1.21 \\
\hline 4 & 1.12 \\
\hline 5 & 0.99 \\
\hline 6 & $0.66 * *$ \\
\hline
\end{tabular}

for respondents with the given characteristic. Each odds ratio measures the effect of a specific characteristic on smoking cessation while controlling for all other study variables. Odds ratios for educational level and number of reasons for smoking cessation are interpreted with reference to the omitted category (non-high school graduate for educational level and none of the six reasons given for smoking cessation).

As shown in Table 3, female respondents and respondents with a smoking history of at least $\mathbf{1 6}$ years were less likely to have successfully quit smoking, whereas older, higher income, and more highly educated respondents were more likely to have quit. These results are consistent with previous research (USDHHS, 1989). Minority status was not significantly associated (positively or negatively) with successful smoking cessation. Previous research has generally reported that minority members are less likely to quit smoking than nonminority members (Novotny, Warner, Kendrick, \& Remington, 1988). Our finding of no association may reflect the controlling influence of additional independent variables in the regression model relating to specific smoking characteristics (years smoked and number of cigarettes per day).

As previously described by Coambs et al. (1992), heavier smokers were less likely to have successfully quit smoking. However, as seen by the interaction of age and smoking intensity, older heavy smokers were more likely to have quit smoking than were younger heavy smokers.

Responding affirmatively to fewer reasons was generally associated with in- 
Table 4. Associations of Reasons for Smoking Cessation With Successful Cessation

\begin{tabular}{lllll}
\hline Reason & Important & $\begin{array}{c}\text { Somewhat } \\
\text { Important }\end{array}$ & $\begin{array}{c}\text { Very } \\
\text { Important }\end{array}$ & $\begin{array}{c}\text { Each Additional } \\
\text { Reason }\end{array}$ \\
\hline Present health & $1.14^{*}$ & 0.89 & $1.24^{* * *}$ & $0.92^{* * * * *}$ \\
Future health & 1.10 & $0.76^{* *}$ & $1.29^{* *}$ & $0.93^{* * *}$ \\
Example for children & $1.25^{* * *}$ & 1.11 & $1.35^{* * * *}$ & $0.89^{* * * *}$ \\
Cost & $0.71^{* * * *}$ & $0.69^{* * * *}$ & $0.73^{* * *}$ & 1.00 \\
Effect on others & $0.87^{*}$ & $0.75^{* * * *}$ & 0.96 & 0.97 \\
Pressure from family & $\mathbf{0 . 7 9 * * *}$ & $0.68^{* * * *}$ & 0.91 & 0.99 \\
\hline
\end{tabular}

$$
*_{p}<.05 . \quad{ }^{* *} p<.01 . \quad * * * p<.001 . \quad{ }^{* * * *} p<.0001 .
$$

creased likelihood of having successfully quit smoking. This may reflect the intensity of motivation for smoking cessation, as discussed in the following.

Results from the logistic regressions for each of the six reasons for smoking cessation are shown in Table 4 . Here, a statistically significant odds ratio greater than 1.0 for a given reason indicates that respondents answering affirmatively to that reason were more likely to have quit smoking than were respondents not giving that reason, whereas a significant odds ratio less than 1.0 indicates decreased likelihood of smoking cessation among respondents answering affirmatively. Again, each odds ratio measures the effect of a specific reason on smoking cessation while controlling for all other study variables.

In regressions examining overall importance (Table 4, column 2), present health, future health and example for children were associated with increased likelihood of successful smoking cessation (although the association of future health was not statistically significant), whereas cost, effect on others, and pressure from friends and family were associated with decreased successful cessation. Present health, future health, and example for children will thus be termed the positive reasons, whereas cost, effect on others, and pressure from friends and family are the negative reasons.

The relative importance given a reason led to notable differences. For the positive reasons, responding that a reason was only somewhat important (column 3) was not associated with increased likelihood of successful cessation (and in the case of future health, was significantly association with decreased quitting); responding that the positive reason was very important (column 4) led to a greater association with quitting. For the negative reasons, the reverse pattern held true. Responding that a reason was only somewhat important had the greatest association with decreased quitting; responding that a reason was very important had less or no significant association with likelihood of smoking cessation.

Table 4 also reports the influence of each additional reason (each reason given in addition to the reason included in that regression model) on the likelihood of successful smoking cessation. For the positive reasons, each additional reason was associated with decreased likelihood of smoking cessation. For the negative reasons, there was no significant effect of additional reasons on quitting. 


\section{DISCUSSION}

Early work by Rosenblatt, Rosen, and Allen (1967) and by Schwartz and Dubitzky (1968) cited three primary reasons for smoking cessation: health concerns, expense, and lack of enjoyment of smoking. In more recent studies, health concerns have emerged as the dominant reasons for smoking cessation (Duncan, Cummings, Hudes, Zahnd, \& Coates, 1992; Lichtenstein \& Cohen, 1990; Schneider, 1984; Swenson \& Dalton, 1983). Other reasons, such as setting an example for children and pleasing a loved one, also have become more prominent (Lichtenstein \& Cohen, 1990; Orleans et al., 1989).

Gilpin et al. (1992) recently published a study examining the relationships between reasons for smoking cessation and successful quitting. Their results were very different than those presented here. Gilpin et al. found that as sole reasons for smoking cessation, cost concerns, health concerns (including present health and future health), and social reasons (including example for children, effect on others, and pressure from family and friends) were all approximately equally associated with successful quitting. In contrast, we have reported that although health concerns are associated with increased likelihood of smoking cessation, cost concerns are associated with decreased likelihood, and social reasons are mixed, with example for children associated with increased likelihood and the other two reasons with decreased likelihood (see Table 4).

A number of factors may explain these major differences. First, Gilpin et al. (1992) based their study on the 1987 National Health Interview Survey (NHIS), where reasons for smoking cessation were asked in an open-ended question (". . . please tell me the reasons you had for trying to quit"), as opposed to the six reasons stated in the AUTS. Many fewer respondents answered positively to each reason in the NHIS as compared to the AUTS; for example, whereas approximately $61 \%$ of AUTS respondents answered affirmatively to quitting or trying to quit for present health concerns, and approximately $77 \%$ for future health concerns (see Table 2), the comparable numbers presented by Gilpin et al. were $13 \%$ and $26 \%$, respectively. As noted before, Gilpin et al. grouped a number of reasons into a broad category of social reasons. We found that not all reasons in this category had similar associations with successful quitting. Furthermore, Gilpin et al. did not control for smoking characteristics (years smoked and number of cigarettes per day) in their logistic regressions. We found these characteristics to be highly (negatively) associated with quitting. As we have found that reasons for smoking cessation are associated with specific smoking characteristics (data not shown), failure to include the smoking characteristics may introduce a bias into the results.

A number of recent studies have focused on the difference between intrinsic and extrinsic motivators for smoking cessation. Curry, Wagner, and Grothaus (1990) found that current smokers with intrinsic motivations (i.e., health related) were more likely to quit successfully than were smokers with extrinsic motivations (i.e., social influence). Other studies have found similar differences between extrinsic and intrinsic factors in maintaining smoking cessation. Harackiewicz, Sansone, Blair, Epstein, and Manderlink (1987) reported that 
quitters who attributed smoking cessation to intrinsic factors were better able to maintain their cessation over time as compared to those identifying extrinsic reasons. In contrast, individuals who relapsed after smoking cessation were more likely to blame this failure on extrinsic factors. Another report (Prochaska, Crimi, Lapsanski, Martel, \& Reid, 1982) noted that individuals successfully abstaining from smoking relied more on experiential (intrinsic) factors, whereas those who relapsed relied more on environmental (extrinsic) factors.

Our study found that personal health concerns (intrinsic reasons) had the strongest association with increased likelihood of successful smoking cessation. However, example for children was also associated with increased success. Smokers may view their children as being different from other extrinsic motivators; because of the bond between parents and children, children may be thought of as intrinsic factors. Also, the wording of the reason, "example for children," has both intrinsic and extrinsic components: Although the driving force behind this reason is extrinsic (children), it has an intrinsic focus (self as an example). This reason is different than potential related reasons without the intrinsic focus, such as protecting children from secondhand smoke.

In general, we found extrinsic reasons, such as cost, to be associated with decreased success in smoking cessation. We found little difference in the effect of cost as a reason for smoking cessation across demographic characteristics, including gender, age, education, minority status, and income (data not shown). This might be interpreted as calling into question the effectiveness of cigarette excise taxes as important motivators for smoking cessation. However, the empirical evidence associating tax increases with smoking decreases is substantial and qualitatively consistent across studies (Peterson, Zeger, Remington, \& Anderson, 1992; USDHHS, 1989). It is plausible that smokers react to price increases without consciously identifying them as a motivation to quit, especially because smokers may underestimate the cost of their smoking by more than half (Holden, 1988). It also is possible that tax increases may be important in discouraging younger individuals from starting to smoke. Prominent economic research has found that younger people exhibited more elasticity of demand for cigarettes than did older individuals (Lewit, Coate, Grossman, 1981; USDHHS, 1989).

As seen in Table 4, the level of importance attributed to a given reason clearly mediated likelihood of cessation. Positive reasons (present health, future health, and example for children) had statistically significant associations with smoking cessation only when these reasons were viewed as very important. On the other hand, negative reasons (cost, effect on others, and pressure from friends and family) were most significantly associated with decreased likelihood of smoking cessation when viewed as only somewhat important.

Responding that either a negative or positive reason was very important may reflect increased motivation, and results in greater positive association (for positive reasons) or decreased negative association (for negative reasons) with successful quitting as compared to a somewhat important response. Differences in motivation and self-efficacy may reflect the dissimilarity between successful and unsuccessful quitters. Successful quitters tend to be highly motivated to stop smoking (Marlatt, Curry, \& Gordon, 1988). Haaga (1990) showed that following quitting, self-efficacy (the ability to plan and carry out actions to reach a desired 
goal) was predictive of maintaining smoking cessation. Tipton and Riebsame (1987) reported that whereas former smokers and never smokers did not differ from each other on a Self-Belief Scale, both showed significantly higher scores than current smokers. Our study suggests that identifying a reason as only somewhat important may indicate decreased concern in that area (as compared to identifying the reason as very important), and hence, decreased motivation for smoking cessation.

A potential limitation of this data is the possible biases introduced by selfreporting of reasons for smoking cessation. It may be that successful quitters increase the importance of their reasons for cessation after they have quit, whereas unsuccessful quitters decrease the importance following failure. Compared with our findings, this potential bias would suggest weaker associations of the positive reasons with having quit smoking and stronger associations of the negative reasons with having failed to quit smoking than are presented here. However, two of the three positive reasons were associated with having successfully quit smoking independent of the level of importance assigned to the reasons (Table 4). This suggests that if there is a bias effect being observed in regards to the positive reasons, the effect is small.

A greater number of reasons given for smoking cessation was associated with decreased likelihood of successful cessation (Table 3). However, the effect of additional reasons differed when examining positive versus negative reasons (Table 4). When a smoker is focused on a single positive reason, each additional reason may diffuse this motivation and decrease the likelihood of cessation. In contrast, when a negative reason is the motivator, the likelihood of cessation is already decreased, and additional reasons do not have any further effect. This may again reflect motivational and self-efficacy differences between successful and unsuccessful quitters.

This analysis was based on responses to the 1986 AUTS. It is uncertain whether the results from this analysis are applicable to motivations for smoking today. This study indicated that intrinsic reasons were most closely associated with successful smoking cessation. In the intervening years, changes in clean indoor air laws and associated social norms, both of which are extrinsic factors, may have become more predominant motivators. The results presented here can serve as a framework for comparing contemporary motivations for smoking cessation. If motivations for successfully quitting have changed from intrinsic to extrinsic, then practices such as regulating indoor smoking may have worked well to stimulate smoking cessation.

\section{REFERENCES}

Coambs, R.B., Li, S., \& Kozlowski, L.T. (1992). Age interacts with heaviness of smoking in predicting success in cessation of smoking. American Journal of Epidemiology, 135, 240-246.

Curry, S., Wagner, E.H., \& Grothaus, L.C. (1990). Intrinsic and extrinsic motivations for smoking cessation. Journal of Consulting and Clinical Psychology, 58, 310-316.

Duncan, C.L., Cummings, S.R., Hudes, E.S., Zahnd, E., \& Coates, T.J. (1992). Quitting smoking: Reasons for quitting and predictors of cessation among medical patients. Journal of General Internal Medicine, 7, 398-404. 
Fiore, M.C., Novotny, T.E., Pierce, J.P., Giovino, G.A., Hatziandreu, E.J., Newcomb, P.A., Surawicz, T.S., \& Davis, R.M. (1990). Methods used to quit smoking in the United States. Do cessation programs help? Journal of the American Medical Association, 263, 2760-2765.

Freund, K.M., D'Agostino, R.B., Belanger, A.J., Kannel, W.B., \& Stokes, J., III. (1992). Predictors of smoking cessation: The Framingham study. American Journal of Epidemiology, 135, 957-964.

Gilpin, E., Pierce, J.P., Goodman, J., Burns, D., \& Shopland, D. (1992). Reasons smokers give for stopping smoking: Do they relate to success in stopping? Tobacco Control, 1, 256-262.

Haaga, D.A.F. (1990). Issues in relating self-efficacy to smoking relapse: Importance of an "Achilles' Heel" situation and of prior quitting experience. Journal of Substance Abuse, 2, 191-200.

Harackiewicz, J.M., Sansone, C., Blair, L.W., Epstein, J.A., \& Manderlink, G. (1987). Attributional processes in behavior change and maintenance: Smoking cessation and continued abstinence. Journal of Consulting and Clinical Psychology, 55, 372-378.

Holden, J. (1988). Effect on the pocket or fear of the grave? The reaction of smokers to information. Practitioner, 232, 660-664.

Kabat, G.C., \& Wynder, E.L. (1987). Determinants of quitting smoking. American Journal of Public Health, 77, 1301-1305.

Klesges, R.C., Somes, G., Pascale, R.W., Klesges, L.M., Murphy, M., Brown, K., \& Williams, E. (1988). Knowledge and beliefs regarding the consequences of cigarette smoking and their relationships to smoking status in a biracial sample. Health Psychology, 7, 387-401.

Lewit, E.M., Coate, D., \& Grossman, M. (1981). The effects of government regulation on teenage smoking. Journal of Law and Economics, 24, 545-569.

Lichtenstein, E., \& Cohen, S. (1990). Prospective analysis of two modes of unaided smoking cessation. Health Education Research, 5, 63-72.

Marlatt, G.A., Curry, S., \& Gordon, J.R. (1988). A longitudinal analysis of unaided smoking cessation. Journal of Consulting and Clinical Psychology, 56, 715-720.

McWhorter, W.P., Boyd, G.M., \& Mattson, M.E. (1990). Predictors of quitting smoking: The NHANES I followup experience. Journal of Clinical Epidemiology, 43, 1399-1405.

Novotny, T.E., Warner, K.E., Kendrick, J.S., \& Remington, P.L. (1988). Smoking by blacks and whites: Socioeconomic and demographic differences. American Journal of Public Health, 78, 1187-1189.

Orleans, C.T., Schoenbach, V.J., Salmon, M.A., Strecher, V.J., Kalsbeek, W., Quade, D., Brooks, E.F., Konrad, T.R., Blackmon, C., \& Watts, C.D. (1989). A survey of smoking and quitting patterns among black Americans. American Journal of Public Health, 79, 176-181.

Peterson, D.E., Zeger, S.L., Remington, P.L., \& Anderson, H.A. (1992). The effect of state cigarette tax increases on cigarettes sales, 1955 to 1988. American Journal of Public Health, 82, 94-96.

Prochaska, J.O., Crimi, P., Lapsanski, D., Martel, L., \& Reid, P. (1982). Self-change processes, selfefficacy, and self-concept in relapse and maintenance of cessation of smoking. Psychological Reports, 51, 983-990.

Rosenblatt, D., Rosen, B., \& Allen, H. (1967). Attitudes, information, and behavior of college students related to smoking and smoking cessation. In S.V. Zagona (Ed.), Studies and issues in smoking behavior. Tucson: The University of Arizona Press.

SAS Institute, Inc. (1986). SUGI supplemental library user's guide: Version 5 edition. Cary, NC: SAS Institute, Inc.

Schneider, S.J. (1984). Who quits smoking in a behavioral treatment program? Addictive Behaviors, 9 , $373-381$.

Schwartz, J.L., \& Dubitzky, M. (1968). Psycho-social factors involved in cigarette smoking and cessation. Berkeley, CA: The Institute for Health Research.

Swenson, I., \& Dalton, J.A. (1983). Reasons for smoking cessation among a random sample of North Carolina nurses. Women and Health, 8, 33-41.

Tipton, R.M., \& Riebsame, W.E. (1987). Beliefs about smoking and health: Their measurement and relationship to smoking behavior. Addictive Behaviors, 12, 217-223.

U.S. Department of Health and Human Services (USDHHS). (1989). Reducing the health consequences of smoking: 25 years of progress. A report of the Surgeon General (DHHS Publication No. CDD 89-8411). Washington, DC: U.S. Government Printing Office.

U.S. Department of Health and Human Services (USDHHS). (1990). Report of the 1986 adult use of tobacco survey. Washington, DC: U.S. Government Printing Office. 